\title{
Multiplicação de Bacillus subtilis em vinhaça e viabilidade no controle da meloidoginose, em cana-de-açúcar
}

\author{
Rodrigo B. Cardozo ${ }^{1}$ \& Fabio F. de Araújo ${ }^{1}$
}

\begin{abstract}
RESUMO
Objetivou-se, com este trabalho, avaliar o controle da meloidoginose e o crescimento da cana-deaçúcar, em função da aplicação de Bacillus subtilis ao solo após multiplicação em vinhaça. Bioensaios foram conduzidos em laboratório com avaliação do crescimento de $B$. subtilis em meio líquido com interesse na melhor composição de meio de cultura, a partir da vinhaça. No experimento em casa de vegetação foi utilizado solo coletado em área de cultivo de cana com histórico de alta infestação com Meloidogyne spp. No solo acondicionado em vasos efetuou-se o plantio da variedade de cana-deaçúcar RB 72454, cujos tratamentos foram: controle; vinhaça pura (50 $\left.\mathrm{m}^{3} \mathrm{ha}^{-1}\right)$; Bacillus subtilis em suspensão aquosa $\left(50 \mathrm{~m}^{3} \mathrm{ha}^{-1}\right) ; B$. subtilis multiplicado na vinhaça para $50 \mathrm{~m}^{3} \mathrm{ha}^{-1}$ e $100 \mathrm{~m}^{3} \mathrm{ha}^{-1}$. A multiplicação de Bacillus subtilis em meio de cultura à base de vinhaça (25\%) foi significativamente superior em comparação com o meio de cultura caldo nutriente. A aplicação de $B$. subtilis em suspensão aquosa promoveu o crescimento e a redução da reprodução dos nematóides em cana-de-açúcar durante o experimento. A aplicação de $B$. subtilis multiplicado na vinhaça não proporcionou os benefícios de estímulo ao crescimento e controle da meloidoginose na cana-de-açúcar, encontrados com a aplicação apenas da bactéria no solo.
\end{abstract}

Palavras-chave: resíduos orgânicos, Meloidogyne, fitopatologia, controle biológico

\section{Multiplication of Bacillus subtilis in vinasse and viability to control root-knot in sugarcane}

\begin{abstract}
This work aimed to evaluate the control of root-knot nematodes and sugarcane growth in function of Bacillus subtilis in soil after multiplication in vinasse. Laboratory tests were developed to define the best concentration of vinasse on the composition of culture medium to optimize the growth of $B$. subtilis. For the experiment in the greenhouse, soil collected in the area of sugarcane cultivation was used. The following treatments were established: control, vinasse $\left(50 \mathrm{~m}^{3} \mathrm{ha}^{-1}\right)$, Bacillus subtilis in aqueous suspension $\left(50 \mathrm{~m}^{3} \mathrm{ha}^{-1}\right) ; B$. subtilis multiplied in vinasse $\left(50\right.$ and $\left.100 \mathrm{~m}^{3} \mathrm{ha}^{-1}\right)$. The multiplication of Bacillus subtilis in pure vinasse $(25 \%)$ was significantly superior when compared to nutrient solution. The application of $B$. subtilis in aqueous solution promoted growth of sugarcane and reduced reproduction of the nematodes in the roots during the experiment. The use of $B$. subtilis, multiplied in vinasse did not achieve the benefits to promote growth and control of nematodes in sugarcane, found with the application of only bacteria in soil.
\end{abstract}

Key words: organic residues, Meloidogyne, phytopathology, biological control 


\section{INTRODUÇÃO}

A vinhaça é um resíduo gerado em grande abundância, nas destilarias de produção de álcool. O resíduo líquido é caracterizado como de coloração escura e produzido na taxa média de $13 \mathrm{~L}$ para cada litro de álcool apresentando, em sua constituição, uma mistura de compostos orgânicos e inorgânicos (Paulino et al., 2011). Já foram estudados os efeitos da aplicação da vinhaça sobre as características e propriedades física, química e mecânica do solo; no entanto, são poucas as informações relativas aos efeitos na propriedade biológica, principalmente sobre a atividade supressiva aos fitopatógenos do solo (Pedrosa et al., 2005).

Com o aumento da área cultivada com cana-de-açúcar, sobretudo no Estado de São Paulo, a cultura se tem expandido para novas fronteiras agrícolas com predomínio de solos pobres e arenosos. Com isto, os problemas fitossanitários na cultura aumentaram, entre os quais se destaca a ação deletéria dos fitonematóides (Moura, 2000). Dinardo-Miranda \& Menegatti (2003) estimam que na cultura da cana-de-açúcar os danos causados pelos nematóides reduzam cerca de $20 \%$ da produção da cultura. Com relação à estratégia de controle, a aplicação de nematicidas na ocasião do plantio se apresenta como a prática mais utilizada, em especial por esta apresentar resultados imediatos. Entretanto, o uso de nematicidas de forma contínua em plantios de cana-de-açúcar tem sido questionado quanto à eficácia do controle e pela inconstância dos resultados (Barros et al., 2003).

A aplicação da vinhaça em grandes volumes no solo proporcionou resultados positivos quanto ao controle de nematóides em cana-de-açúcar (Pedrosa et al., 2005). É possível que o efeito do resíduo estudado esteja associado àqueles atribuídos à adição de matéria orgânica que, segundo Lordello (1984), está relacionado à liberação de ácidos graxos voláteis nocivos aos nematóides, além de criar condições favoráveis à proliferação de micro-organismos que atuam como inimigos naturais desses fitoparasitos (Rodriguez-Kábana, 1986). Apesar disto, a utilização de dosagens menores de vinhaça precisa ser mais investigada haja vista que o aporte de matéria orgânica ao solo é menor.

Uma opção viável para o controle de fitonematóides que não seja o controle químico convencional nem a utilização de dosagens excessivas de resíduos orgânicos, é o controle biológico (Coimbra \& Campos, 2005). Algumas espécies microbianas, como os estreptomicetos e Bacillus subtilis, foram avaliadas como interferentes no ciclo dos fitonematóides apresentando potencial para utilização no controle dos parasitas no solo (Kavitha et al. 2007; Sousa et al., 2006). Ficou demonstrado que isolados de $B$. subtilis não apenas produzem metabólitos tóxicos que afetam o movimento de nematóides mas também podem inibir a eclosão de juvenis e o processo pelo qual eles penetram nas raízes (Araújo et al., 2002). Além disto, a produção de proteases por Bacillus subtilis (Lian et al., 2007) e a indução de enzimas de defesa na planta hospedeira (Kavitha et al., 2007) são mecanismos atribuídos à rizobactéria no controle dos fitonematóides.

Lodo de estação de tratamento de efluentes foi avaliado como meio de cultura para Bacillus subtilis com resultados de multiplicação da bactéria considerados satisfatórios (Araújo et al., 2006). O resíduo sucroalcoleiro apresenta características químicas favoráveis ao desenvolvimento de micro-organismos destacando-se a concentração de matéria orgânica e açúcares totais (Shi \& Zhu, 2007). Além do mais, vários grupos de microorganismos são estimulados para multiplicação após a aplicação de resíduos orgânicos no solo, os quais podem estar envolvidos em algum modo de ação de controle biológico dos nematóides (Araújo \& Bettiol, 2005).

Com a justificativa de se estudar a viabilidade do controle de nematóides por Bacillus subtilis e também da necessidade de se aliar a disposição da vinhaça no solo ao controle biológico objetivou-se, com este trabalho, avaliar a multiplicação da bactéria em vinhaça e sua aplicação no controle de nematóides e crescimento de cana cultivada em solo naturalmente infestado com o parasita.

\section{MATERIAL E MÉTODOS}

O presente trabalho foi desenvolvido no período de novembro de 2007 a outubro de 2008, em Presidente Prudente, SP. Utilizaram-se amostras de vinhaça concentrada $\left(40^{\circ}\right.$ Brix e $30 \%$ de matéria seca) obtidas na empresa Destilaria Santa Eliza, Penápolis, SP. O resíduo foi analisado em laboratório para a determinação de composição química apresentando a seguinte concentração de macronutrientes em base seca $\left(\mathrm{g} \mathrm{kg}^{-1}\right): 9,2 \mathrm{de}$ $\mathrm{N}$; 0,5 de P; 15,1 de K; 3,3 de Ca; 3,3 de Mg; 5,8 de S. O pH $\left(\mathrm{CaCl}_{2}\right)$ do resíduo era 3,9. O isolado de Bacillus subtilis utilizado nos experimentos foi o AP-3, relatado como promotor de crescimento de plantas (Araújo et al., 2005).

Para avaliação do crescimento de B. subtilis em vinhaça, formulações de meio de cultura foram preparadas com doses crescentes de vinhaça, ajustando-se os seguintes tratamentos: Vinhaça concentrada; $50 \%$ de vinhaça $+50 \%$ de água destilada e $25 \%$ de vinhaça $+75 \%$ de água destilada e meio de cultura padrão (caldo nutriente). Os meios foram preparados para volume final de $50 \mathrm{~mL}$ acondicionados em erlenmeyer $(250 \mathrm{~mL})$. $\mathrm{O}$ pH de todos os meios utilizados foi ajustado para 7,0. O meio de cultura caldo nutriente foi preparado à base de peptona $(5$ $\left.\mathrm{g} \mathrm{L}^{-1}\right)$ e extrato de levedura $\left(3 \mathrm{~g} \mathrm{~L}^{-1}\right)$. Os meios de cultura foram autoclavados $\left(121{ }^{\circ} \mathrm{C}\right.$ por $20 \mathrm{~min}$.) e após resfriamento inoculados com $1 \mathrm{~mL}$ de suspensão de Bacillus subtilis (AP-3) em água destilada, contendo aproximadamente $1.10^{8} \mathrm{ufc} \mathrm{mL}^{-1}$. Os recipientes, após inoculação, foram colocados em mesa agitadora orbital (120 rpm) e deixados sob agitação a temperatura ambiente, durante cinco dias. Decorrido este período avaliou-se a concentração de bactérias no meio de cultura, pelo método de diluição seriada e a contagem de unidades formadoras de colônias em placas com meio ágar nutriente. Todas as determinações de crescimento foram feitas em triplicata.

No meio de cultura que apresentou a maior concentração bacteriana foi determinada, também, a curva de crescimento de Bacillus subtilis. Para isto, após a inoculação do Bacillus subtilis neste meio de cultura e conforme já descrito, o mesmo foi colocado em mesa agitadora orbital (120 rpm) durante sete dias realizando-se a contagem diária da concentração de 
bactérias no meio, pelo método de diluição seriada e contagem em placas com meio ágar nutriente.

Para avaliação do efeito da introdução de B. subtilis no solo sobre o crescimento da cana, conduziu-se um experimento de casa de vegetação. Inicialmente, foram coletadas amostras de solo em área agrícola, sob cultivo de cana, da Usina Alto Alegre, Presidente Prudente, SP, com histórico de alta infestação por nematóides. Pela análise de extração de nematóides do solo realizada conforme descrito em Araújo \& Bettiol (2005), detectou-se a presença de 200 juvenis de Meloydogine spp em $100 \mathrm{~cm}^{3}$ de solo. A análise de fertilidade do solo realizada segundo van Raij et al. (2001), apresentou os seguintes valores: $\mathrm{pH}\left(\mathrm{CaCl}_{2}\right)-5,0 ; 14 \mathrm{~g} \mathrm{dm}^{-3}$ de M.O.; $6 \mathrm{mg} \mathrm{dm}^{-3}$ de P; 2,5 mmol $\mathrm{dm}^{-3} \mathrm{de} \mathrm{K} ; 14 \mathrm{mmol}_{\mathrm{c}} \mathrm{dm}^{-3} \mathrm{de} \mathrm{Ca} ; 4 \mathrm{mmol}_{\mathrm{c}} \mathrm{dm}^{-3} \mathrm{de}$ $\mathrm{Mg} ; 36 \mathrm{mmol}_{\mathrm{c}} \mathrm{dm}^{-3}$ de CTC e $58 \%$ de saturação de bases. As amostras de solo coletadas foram homogeneizadas, peneiradas e colocadas em vasos com capacidade de $15 \mathrm{~kg}$ de solo. A variedade de cana-de-açúcar RB 72454 foi plantada nos vasos pela transferência de colmo contendo cinco gemas. Para a condução do experimento foram deixados dois perfilhos por vaso.

O experimento foi delineado em blocos inteiramente casualizados, com cinco tratamentos e quatro repetições. Os tratamentos foram efetivados pela aplicação de B. subtilis multiplicado na vinhaça e suspenso em água, sendo dispostos da seguinte forma e respectivas taxas de aplicação: 1 - Controle; 2 - vinhaça $\left(50 \mathrm{~m}^{3} \mathrm{ha}^{-1}\right) ; 3$ - Bacillus subtilis em suspensão aquosa $\left(50 \mathrm{~m}^{3} \mathrm{ha}^{-1}\right)$; 4 - Bacillus subtilis multiplicado em vinhaça $\left(50 \mathrm{~m}^{3} \mathrm{ha}^{-1}\right)$ e 5 - Bacillus subtilis multiplicado em vinhaça (100 $\mathrm{m}^{3}$ ha). No tratamento Bacillus subtilis em suspensão aquosa utilizaram-se células multiplicadas em tubos com meio sólido as quais foram, posteriormente, raspadas e diluídas em água para concentração final de $5,0 \times 10^{8}$ células $\mathrm{mL}^{-1}$. Nos tratamentos em que o Bacillus subtilis foi multiplicado em vinhaça utilizouse o meio de cultura com melhor desempenho de crescimento de $B$. subtilis na etapa anterior, obtendo-se a concentração final de 5,0 × $10^{8}$ células $\mathrm{mL}^{-1}$. As aplicações de todos os tratamentos foram distribuídas em três épocas (30,60 e 90 dias) após o plantio da cana. Durante este período foi efetuada a reposição hídrica mantendo-se a umidade do solo próximo à capacidade de campo.

Para avaliação do crescimento da cana foi efetivada, inicialmente, a medição de altura das plantas, aos 90 dias; aos 105 dias as plantas foram retiradas dos vasos e separada a parte aérea das raízes. A parte aérea foi cortada próximo à raiz e acomodada em sacos de papel, que foram levados ao laboratório; logo após, as amostras foram acondicionadas em estufa de ventilação forçada $\left(60^{\circ} \mathrm{C}\right)$ até peso constante visando à determinação da massa seca de parte aérea. As raízes foram lavadas em água corrente para a retirada da terra aderida superficialmente; em seguida, foram acomodadas na bancada sob temperatura ambiente, durante $12 \mathrm{~h}$, visando à perda do excesso de umidade; em continuação, as raízes foram pesadas e submetidas à extração de juvenis e ovos de Meloidogyne spp. Seguindo-se metodologia descrita por Araújo \& Bettiol (2005). Após a contagem dos juvenis (J2) e dos ovos de Meloidogyne spp. em câmara de Peters efetivaram-se os cálculos de diluição para expressão dos resultados em juvenis e ovos do nematóide por grama de raiz de cana.

Os dados obtidos foram transformados (raiz quadrada + 0,5) e submetidos à análise de variância utilizando-se o programa Sisvar (Ferreira, 2000). De acordo com os valores de F obtidos nas análises de cada variável, realizou-se teste de comparação de média, empregando-se o teste t $(5 \%)$.

\section{Resultados E DisCUSSÃo}

A vinhaça apresentou-se viável para uso como meio de multiplicação de Bacillus subtilis, já que no bioensaio de crescimento bacteriano os resultados revelaram desempenho satisfatório do crescimento de $B$. subtilis quando comparado com o meio caldo nutriente (Tabela 1). A melhor performance de crescimento ocorreu no tratamento com meio de cultivo à base de $25 \%$ de vinhaça; este tratamento superou, de forma significativa, os outros tratamentos, inclusive o caldo nutriente (meio padrão), podendo então ser recomendado para utilização na multiplicação de $B$. subtilis. A recomendação para diluição da vinhaça vai de encontro à presença de baixas concentrações de ácidos alifáticos, aldeídos e alcoóis que são tóxicos para células bacterianas (Couallier et al., 2006). Por outro lado, a biodegradação da vinhaça aumenta da concentração de ácidos orgânicos no meio com a consequente redução do $\mathrm{pH}$ e inibição do crescimento bacteriano (Cibis et al., 2006); entretanto, os resultados encontrados confirmam que a vinhaça pode ser utilizada como meio de cultura para a produção de esporos de B. subtilis, conforme Shi \& Zhu (2007), os quais concluíram que o resíduo contém concentrações consideráveis de material orgânico e inorgânico solúveis disponíveis ao crescimento bacteriano.

Tabela 1. Crescimento de Bacillus subtilis em unidades formadoras de colônia (UFC) por $\mathrm{mL}$ durante cinco dias, utilizando-se diferentes concentrações de vinhaça ${ }^{*}$

\begin{tabular}{lc}
\hline Tratamentos & UFC $\left(\mathbf{x} 1 \mathbf{0}^{8}\right) \mathbf{~ m L}^{-1}$ \\
Vinhaça pura & $1,30 \mathrm{~b}$ \\
Vinhaça $50 \%$ & $1,91 \mathrm{~b}$ \\
Vinhaça 25\% & $11,50 \mathrm{a}$ \\
Caldo nutriente & $1,81 \mathrm{~b}$ \\
DMS & 0,95 \\
CV (\%) & 27,10 \\
\hline
\end{tabular}

* Médias seguidas de mesma letra não diferem pelo teste t (5\%)

A curva de crescimento de $B$. subtilis no meio de cultura à base de vinhaça (25\%), de melhor desempenho no bioensaio anterior, denominado meio V25, durante sete dias, demonstrou que o pico de crescimento bacteriano aconteceu entre o quinto e o sexto dia (Figura 1). Este período pode ser indicado para produção da bactéria com a finalidade de obtenção de maiores concentrações de células. O modelo quadrático foi o que melhor se ajustou para representar a curva de crescimento bacteriana com coeficiente de regressão $\left(\mathrm{R}^{2}\right)$ significativo a $5 \%$ de probabilidade.

Com base na definição da melhor concentração de vinhaça e no período de crescimento para multiplicação de B. subtilis, conduziu-se o experimento com a aplicação dos tratamentos 


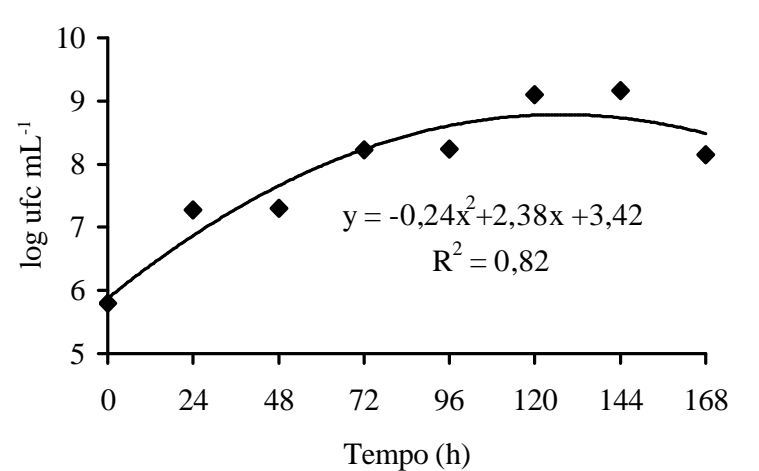

Figura 1. Curva de crescimento em unidade formadora de colônias (ufc) de $B$. subtilis em meio de cultura à base de vinhaça $(25 \%)$

no cultivo de cana em solo infestado com nematóides. Na Tabela 2 se tem o resumo da análise de variância, na qual se observou que apenas na massa seca de raiz não ocorreu diferenças significativas entre os tratamentos.

O tratamento representado apenas pela presença de Bacillus subtilis em suspensão aquosa, proporcionou aumento significativo na altura das plantas e massa seca da parte aérea, aos 90 e 105 dias após o plantio, respectivamente, em comparação com a testemunha (Tabela 3). Este resultado confirma a ação promotora de crescimento em plantas, proporcionada por Bacillus subtilis (AP-3) já relatada em avaliação de crescimento de plantas (Araújo, 2008). Os tratamentos associados à vinhaça com e sem $B$. subtilis não alteraram significativamente o crescimento da parte aérea da cana. Em trabalho com a utilização de vinhaça para controle de nematóides em solo, Pedrosa et al. (2005) também não encontraram alteração de crescimento da planta aos 90 dias após inoculação dos nematóides, com a aplicação de doses de 50 a $1000 \mathrm{~m}^{3} \mathrm{ha}^{-1}$ de vinhaça.

Observou-se, na avaliação de reprodução do nematóide, que apenas o tratamento $B$. subtilis, não multiplicado na vinhaça, proporcionou redução significativa na quantidade de ovos e juvenis do nematóide, nas raízes da cana (Figura 2). $\mathrm{O}$ tratamento apenas com a vinhaça $\left(50 \mathrm{~m}^{3} \mathrm{ha}^{-1}\right)$ não inibiu a reprodução do nematóide demonstrando que a vinhaça na concentração aplicada não proporciona controle do parasita. Sharma \& Khan (1995) avaliando a adubação mineral e a infestação Meloidogyne incognita em tomateiro, concluíram que a adição de potássio em concentrações superiores às da adição de nitrogênio e fósforo favoreceu o parasita, salientando-se que pela análise química efetuada no resíduo foi observada maior concentração de potássio que os outros nutrientes. Por outro lado, Pedrosa et al. (2005) afirmaram que a aplicação de doses de vinhaça acima de $500 \mathrm{~m}^{3}$ ha ${ }^{-1}$ foi eficaz no controle de nematóides em cana-de-açúcar.
Tabela 3. Altura de plantas aos 90 dias e massa seca da parte aérea aos 105 dias após o plantio em cana cultivada em solo infestado com nematóides em função da aplicação $B$. subtilis em suspensão aquosa e multiplicado em meio com $25 \%$ de vinhaça (V25)

\begin{tabular}{lcc}
\hline \multicolumn{1}{c}{ Tratamentos } & $\begin{array}{c}\text { Altura de } \\
\text { plantas }(\mathbf{c m})\end{array}$ & $\begin{array}{c}\text { Massa da parte aérea } \\
\text { seca (g planta-1) }\end{array}$ \\
Controle & $74,8 \mathrm{~b}^{1}$ & $20,50 \mathrm{~b}$ \\
Vinhaça $\left(50 \mathrm{~m}^{3} \mathrm{ha}^{-1}\right)$ & $82,0 \mathrm{ab}$ & $24,00 \mathrm{ab}$ \\
B. subtilis $\left(50 \mathrm{~m}^{3} \mathrm{ha}^{-1}\right)$ & $95,5 \mathrm{a}$ & $29,25 \mathrm{a}$ \\
B. subtilis $\mathrm{V} 25\left(50 \mathrm{~m}^{3} \mathrm{ha}^{-1}\right)$ & $82,3 \mathrm{ab}$ & $20,50 \mathrm{~b}$ \\
B. subtilis V25 $\left(100 \mathrm{~m}^{3} \mathrm{ha}^{-1}\right)$ & $87,5 \mathrm{ab}$ & $24,75 \mathrm{ab}$ \\
DMS & 19,3 & 6,51 \\
\hline Médias seguidas de mesma letra em cada coluna não diferem estatisticamente pelo teste $\mathrm{t}(5 \%)$
\end{tabular}

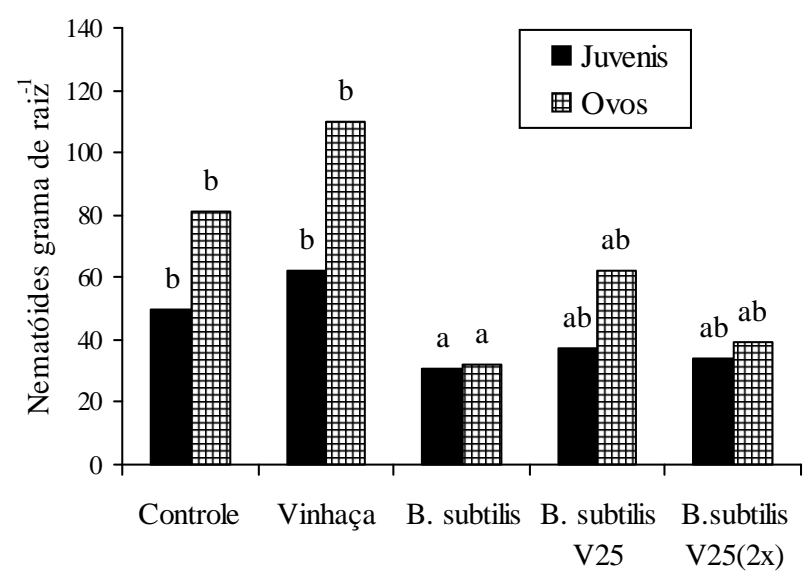

Colunas de mesma cor e mesma letra não diferem pelo teste $t(5 \%)$

Figura 2. Juvenis e ovos de Meloidogyne sp em raízes de cana cultivada em solo infestado com nematóides, em função da aplicação $B$. subtilis em suspensão aquosa e multiplicado em meio com $25 \%$ de vinhaça (V25). Experimento de casa de vegetação

A presença de Bacillus subtilis no solo proporcionou redução na reprodução do nematóide na raiz da cana embora o mecanismo de supressão não tenha sido determinado (Figura 2). Estudando este mesmo efeito do B. subtilis sobre Meloidogyne incognita, em beterraba açucareira, Kavitha et al. (2007), concluíram que o aumento na atividade de enzimas de defesas em plantas tratadas com a bactéria pode ter contribuído para o controle do parasita. Araújo et al. (2002) concluíram, estudando o efeito de $B$. subtilis sobre o nematóide Heterodera javanica, que umas das formas de ação da bactéria sobre o parasita seria na orientação dos nematóides no solo. Em outro trabalho, avaliando o controle biológico proporcionado por $B$. subtilis, relatou-se que a rizobactéria reduz a reprodução dos nematóides de galha em raiz de tomate

Tabela 2. Resumo da análise de variância das variáveis altura de plantas, massa seca de raiz, massa seca da parte aérea, número de ovos e juvenis de nematóides

\begin{tabular}{lcccccc}
\hline \multicolumn{1}{c}{ Fonte de variação } & \multirow{2}{*}{ G.L. } & \multicolumn{3}{c}{ Quadrado médio } \\
\cline { 3 - 7 } & & Altura & Raiz & Parte aérea & Ovos & Juvenis \\
Tratamentos & 4 & $0,72^{*}$ & $1,64^{\text {n.s }}$ & $0,52^{*}$ & $15,14^{\star}$ & $3,35^{\star}$ \\
Resíduo & 15 & 0,35 & 2,37 & 0,20 & 5,58 & 0,88 \\
CV (\%) & & 5,80 & 18,7 & 9,29 & 25,0 & 14,4 \\
\hline
\end{tabular}

* Significativo pelo teste $\mathrm{F}(\mathrm{P}<0,05)$, ns - não significativo 
diminuindo a quantidade de ovos do parasita apresentando, desta forma, uso potencial para programas de manejo integrado da meloidoginose em tomateiro (Jonathan et al., 2000; Araújo \& Marchesi, 2009). Recentemente, foi descrita a associação das proteases microbianas produzidas por Bacillus como fatores de virulência contra os nematóides (Lian et al., 2007).

Pode-se afirmar que o controle biológico da meloidoginose em cana-de-açúcar com $B$. subtilis é uma alternativa promissora para compor programas de controle integrado do parasita no solo. Observa-se também que a bactéria, quando multiplicada em vinhaça, teve sua ação reduzida sobre a reprodução do nematóide. A presença do resíduo no solo nas doses utilizadas, pode ter favorecido o parasita e dificultado a ação de controle do nematóide proporcionada por B. subtilis.

\section{CONCLUSÕES}

1. A multiplicação de Bacillus subtilis em meio de cultura à base de vinhaça apresentou desempenho semelhante com o meio de cultura padrão avaliado.

2. A aplicação de $B$. subtilis em suspensão aquosa promove o crescimento da cana-de-açúcar e reduz a reprodução dos nematóides de galhas.

3. A multiplicação de $B$. subtilis em vinhaça não proporciona os benefícios encontrados na aplicação apenas da bactéria, quanto ao controle da meloidoginose na cana-de-açúcar.

\section{LiTERATURA CITADA}

Araujo, F. F. Inoculação de sementes com Bacillus subtilis, formulado com farinha de ostra e desenvolvimento de milho, soja e algodão. Ciência e Agrotecnologia, v.2, p.456-462, 2008.

Araújo F. F; Aires, A. C. A.; Farina, F. R. Lodo industrial como alternativa de meio de cultura para Bacillus subtilis. Coloquium Agrarie, v.2, p.1-5, 2006.

Araújo, F. F.; Bettiol, W. Supressividade dos nematóides Meloygogine javanica e Heterodera glycines em soja por adição de lodo de esgoto ao solo. Ciência Rural, v. 35, p.806812, 2005.

Araújo, F. F.; Henning, A.; Hungria, M. Phytohormones and antibiotics produced by Bacillus subtilis and their effects on seed pathogenic fungi and on soybean root development. World Journal of Microbiology \& Biotechnology, v.21, p.1639-1645, 2005.

Araújo, F. F.; Marchesi, G. V. P. Uso de Bacillus subtilis no controle da meloidoginose e na promoção do crescimento do tomateiro. Ciência Rural, v.39, p.1558-1561, 2009.

Araújo, F. F.; Silva, J. F. V.; Araújo, A. S. F. Influência de Bacillus subtilis na eclosão, orientação e infecção de Heterodera glycines em soja. Ciência Rural, v.32, p.197-202, 2002.

Barros, A. C. B.; Moura, R. M.; Pedrosa, E. M. R. Influência da aplicação conjunta de nematicida com calcário, cupinicida ou torta de filtro na eficiência do nematicida em cana-deaçúcar. 236 p. In: Congresso Brasileiro de Nematologia, 25, Petrolina, Anais... Petrolina: EMBRAPA, 2003. CD-Rom
Cibis E, Krzywonos, M, Miœkiewicz, T. Aerobic biodegradation of potato slops under moderate thermophilic conditions: effect of pollution load. Bioresource Technology, v.4, p.679$85,2006$.

Coimbra, J. L.; Campos, V. P. Efeito de exsudatos de colônias e de filtrados de culturas de actinomicetos na eclosão, motilidade e mortalidade de juvenis do segundo estádio de M. javanica. Fitopatologia Brasileira, v.30, p.232-238, 2005.

Couallier, E. M.; Payot, T.; Bertin, A. P.; Lameloise, M. L. Recycling of distillery effluents in alcoholic fermentation. Applied Biochemistry and Biotechnology, v.133, p.217-237, 2006.

Ferreira, D. F. Análises estatísticas por meio do Sisvar para Windows versão 4.0. In: Reunião Anual da Região Brasileira da Sociedade Internacional de Biometria, 45, 2000, São Carlos. Anais... São Carlos: UFSCar, 2000. 3p.

Jonathan, E. I.; Barker, K. R.; Abdel-Alim, F. F.; Vrain, T. C.; Dickson, D. W. Biological control of Meloidogyne incognita on tomato and banana with rhizobacteria, actinomycetes and Pausteria penetrans. Nematropica, v.30 p.231-240, 2000.

Kavitha, J.; Jonathan, E. I.; Umamaheswari, R. Field application of Pseudomonas fluorescens, Bacillus subtilis and Trichoderma viride for the control of Meloidogyne incognita in sugarbeet. Journal of Biological Control, v.21, p.211-215, 2007.

Lian L. H.; Tian, B. Y.; Xiong, M. Z.; Zhu, M. Z. Xu, J.; Zhang, K. Q. Proteases from Bacillus: A new insight into the mechanism of action for rhizobacterial suppression of nematode populations. Letters in Applied Microbiology, v.45, p.262-269, 2007.

Lordello, L. G. E. Métodos gerais de controle. In: Lordello, L. G. E (ed.) Nematóides das Plantas Cultivadas. São Paulo: Nobel, 1984. p.81-123.

Miranda, L. L. D.; Menegatti, C. C. Danos causados por nematóides a variedades de cana-de-açúcar em cana planta. Nematologia Brasileira, v.27, p.69-73, 2003.

Moura, R. M. Controle integrado de nematóides da cana-deaçúcar no Nordeste do Brasil. In: Congresso Brasileiro de Nematologia, 22, 2000, Uberlândia. Anais... Uberlândia: UFU, 2000. p. 88-94.

Paulino, J.; Zolin, C. A.; Bertonha, A.; Freitas, P. S. L.; Folegatti, M. V. Estudo exploratório do uso da vinhaça ao longo do tempo.II. Características da cana-de-açúcar. Revista Brasileira Engenharia Agrícola e Ambiental, v.15, p.244-249, 2011.

Pedrosa, E. M. R; Rolim, M. M.; Albuquerque, P. H. S.; Cunha, A. C.. Supressividade de nematóides em cana-de-açucar por adição de vinhaça ao solo. Revista Brasileira Engenharia Agrícola e Ambiental, v.9, p.197-201, 2005.

Rodriguez-Kabana, R. Organic and inorganic nitrogen amendments to soil as nematode suppressants. Journal of Nematology, v.18, p.129-135, 1986.

Sharma G. C.; Khan, M. L. Effect of NPK fertilizers on Meloidogyne incognita infestation and plant growth in tomato. Indian Journal of Nematology, v. 25, p.147-149, 1995. 
Shi, F.; Zhu, Y. Application of statistically-based experimental designs in medium optimization for spore production of Bacillus subtilis from distillery effluent. Biocontrol, v.52, p.845-853, 2007.

Silveira, J. A. G.; Crocomo, O. J. Assimilação de nitrogênio em cana-de-açúcar cultivada em presença de elevado nível de $\mathrm{N}$ e de vinhaça no solo. Revista Brasileira de Fisiologia Vegetal, v.2, p.7-15, 1990.
Sousa, C. S.; Soares, A. C. F.; Garrido, M. S.; Almeida, G. M. C. O. Estreptomicetos no controle da meloidoginose em mudas de tomateiro. Pesquisa Agropecuária Brasileira, v.41, p.17591766, 2006.

van Raij, B.; Andrade, J. C.; Cantarella, H.; Quaggio, J. A. Análise química para avaliação da fertilidade de solos tropicais. Campinas: IAC, 2001. 284p. 